\title{
CDS Primleri ve Derecelendirme (Raiting) Notları ile BIST 100 Endeksi Arasındaki İlişkinin İncelenmesi: Türkiye Örneği
}

Hakan SARITAŞ ${ }^{1}$ - Emre KILIÇ ${ }^{2}$ Elif Hilal NAZLIOĞLU ${ }^{3}$

Makale Gönderim Tarihi: 6 Ocak 2021

Makale Kabul Tarihi: 30 Ağustos 2021

\section{Öz}

Ülke ekonomilerinde yer alan ekonomik birimler açısından CDS primleri ve kredi derecelendirme notları finansal piyasalara ilişkin riskin bir göstergesi olarak dikkate alınmaktadır. Bu bağlamda çalışmada CDS primleri ve kredi derecelendirme notları ile BIST 100 endeksi arasındaki ilişki Türkiye özelinde incelenmiştir. Araştırmanın ekonometrik analiz bölümünde 2010:022020:02 dönemi kullanılmıştır ve ARDL eşbütünleşme testinden yararlanılmıştır. Analiz sonuçları doğrultusunda değişkenler arasında eşbütünleşme ilişkisinin var olduğu tespit edilmiştir. Yani Türkiye için ilgili örneklem döneminde CDS primleri, kredi derecelendirme notları ve BIST 100 endeksinin birlikte hareket ettiği sonucuna ulaşılmıştır.

Anahtar Kelimeler: CDS Primleri, Kredi Derecelendirme Notlar1, BIST 100, ARDL Eşbütünleşme

JEL Kodları: C22, G10, G24

1 Pamukkale Üniversitesi, İktisadi ve İdari Bilimler Fakültesi, İşletme, Muhasebe ve Finansman Bölümü, +90 (258) 296 2688, hsaritas@pau.edu.tr, ORCID:https://orcid.org/0000-0002-7789-782X

2 Nişantaşı Üniversitesi, İktisadi, İdari ve Sosyal Bilimler Fakültesi, Sermaye Piyasaları ve Portföy Yönetimi Bölümü, +90 (507) 470 1757, emre.kilic@nisantasi.edu.tr,ORCID: https://orcid.org/0000$\underline{0003-2900-5123}$ (Sorumlu Yazar)

3 Pamukkale Üniversitesi, Denizli Sosyal Bilimler Meslek Yüksek Okulu, Otel Lokanta ve İkram Hizmetleri, Turizm ve Otel İşletmeciliği Bölümü, +90 (258) 296 7494,enazlioglu@pau.edu.tr, ORCID: https://orcid.org/0000-0002-4425-7479 


\title{
Analysis of the Relationship Between Credit Default Swaps (CDS), Credit Ratings and Stock Markets: The Case of Turkey
}

\begin{abstract}
In terms of economic agents, CDS premiums and credit ratings are considered as an indicator of the risk related to financial markets. In this context, relationship between CDS and credit ratings with BIST 100 index was examined for Turkey in particular In the econometric analysis part of the study, the period 2010:02-2020:02 was used and the ARDL co-integration test was imposed on. Analysis results showed that the variables are co-integrated. In other words, it is concluded that CDS premiums, credit rating scores and BIST 100 index move together in the relevant sample period for Turkey.
\end{abstract}

Keywords: CDS Premiums, Credit Rating Scores, BIST, ARDL Co-integration JEL Codes: C22, G10, G24

\section{Giriş}

Küreselleşme olgusu finansal piyasaların entegre olmasını sağlamaktadır. Finansal piyasalar arasındaki serbestleşme ve genişleme uluslararası sermayenin yer değiştirmesini daha kolay hale getirmiştir. Uluslararası finansal yatırımcılar yatırım yapacakları zaman risklerden korunmak, piyasalardaki olumsuzluklardan etkilenmemek ve en uygun yatırımı yapabilmek için göstergelerden faydalanmaktadırlar. Yatırımcılar piyasaları seçerken ülkelerin kredi risklerini gösteren kredi derecelendirme notları ve özellikle 2000'lerden sonra kullanımı öne çıkan kredi temerrüt takas (CDS) primi bilgilerini kullanmaktadırlar. Hisse senedi piyasasında CDS, yatırımın derecesini yönlendirmektedir (Fung, Sierra ve Yau, 2008).

CDS'ler şirketler ve ülkelerin temerrüde düşme olasıllı̆g 1 için kullan1lan finansal araçlardan biridir. Kısaca CDS primi ülkelerin kredi riski bilgisini vermektedir. CDS priminin yüksek olması ülke riskinin yüksek olduğunu göstermektedir. CDS'lerin diğer kredi risk göstergelerine göre başlıca farkı primlerin günlük bazda ayarlanıyor olması ve mevcut koşulları yansıtmasıdır. Kredi derecelendime notları ise kredi derecelendirme şirketleri (kuruluşları) tarafından ülkelerin, şirketlerin ve kurumların kredi değerliliğinin belirlenmesinde, yükümlülüklerini tam olarak ve zamanında yerine getirip getiremeyeceği ile ilgili verilen notlardır. Bu notlar sayesinde ülkelerin aralarında yapacakları borçlanmalara yön verilebilmektedir (Yıldırım, Yıldız ve Ayde- 
mir, 2018). Ayrıca finansal istikrar olgusunun ekonomik gelişmişlik düzeyi ile ilgisinden dolayı yine Türkiye borsasının ilgili değişkenlerle ilişkisi ve bir gösterge olması önem arz etmektedir. Son yıllarda yaşanan finansal krizlerin özellikle 2008 Küresel Ekonomik Krizi ve 2010 Avrupa Borç Krizi gibi derecelendirme notlarının güvenilirliği ile ilgili şüphe oluşturmaktadır. Bundan dolayı CDS özelinde pay piyasalarının derinliğinin ve genişliğinin artırılması finansal istikrara da katkı sağlayarak ülke riskinin azalmasına katkı sağlayabilecektir.

CDS primi, kredi derecelendirme notları ve Borsa İstanbul arasındaki ilişki farklı değişkenler de dahil edilerek ele alınmış olup, konuya ilişkin birçok çalışma yapılmıştır. Bu çalışmalarda birbirinden farklı sonuçlara ulaş1lmıştır. Kaya, Kaya ve Yalçıner (2015), iyi ve kötü olaylar için bir değerlendirme yapıldığında kredi derecelendirme notlarının CDS primlerine nazaran daha fazla olayın etkisini içeriğinde barındırdığını ifade etmektedir. Bursa ve Kadılar (2016), BIST 100 endeksinin değerinin bilinmesinin CDS hakkındaki belirsizliği büyük ölçüde kaldırdığını ifade etmektedirler. Çelik ve Koç (2016), CDS ve borsa arasında iki yönlü nedensellik ilişkisi olduğu, ülke riskindeki bir değişikliğin, borsa performansında da değişikliğe neden olduğu ve borsadaki değişikliğin ülke riskinde de değişikliğe neden olduğunu tespit etmişlerdir. Şahin ve Özkan (2018), CDS ile BIST 100 arasında çift yönlü nedensellik ilişkisi olduğu, BIST 100 ile döviz kurları arasında ise nedensel bir ilişkinin olmadığı sonucuna ulaşmışlardır.

CDS primleri ülke risklerini temsil ettiği için gelişmekte olan ülkelerde erken uyarı göstergesi olarak kullanılabilmektedir. Türkiye gelişmekte olan ülkeler grubunda yer aldığ 1 için ülke riski küresel piyasalarda önem arz etmektedir. Kredi derecelendirme notları da ülke kredi riskliliğinin bir göstergesidir. Türkiye'ye ilişkin bu notların yıllardan beri tartışmalı olması bu konunun araştırılmasını önemli kılan bir noktadır. Bu nedenle çalışmamızda elde ettiğimiz bulgular literatüre ilgili tartışma noktasında da katkı sağlayacaktır. Hem kredi derecelendirme notları hem de CDS primleri ülkelerin finansal piyasalarını ve finansal araçlarını etkileyen faktörlerdir. Ayrıca pay senedi piyasalarının finansal gelişmişliğin bir göstergesi olması nedeniyle BIST 100 ile CDS ve derecelendirme notları ilişkilerinin incelenmesi önem arz etmektedir. Çalışmada Türkiye'nin pay piyasası ile CDS ve kredi derecelendirme notları arasındaki ilişki ARDL eşbütünleşme yöntemi ile analiz edilmektedir. Analiz için ilgili değişkenlere ait 2010:2-2020:2 dönemini kapsayan aylık veriler kullanılmıştır. Bulgular literatürdeki sonuçlara paralel olarak CDS ve BIST 100 arasında beklenen ters yönlü ilişkiyi desteklemektedir. Literatürden farklı olan durum ise kredi derecelendirme notları ile BIST 100 arasında ortaya ç1- 
karmaktadır. Kredi derecelendirme notları artarken BIST 100'ün de artmas1 gerekirken tam tersi bir durum olduğu tespit edilmiştir.

Çalışmanın buradan sonraki bölümleri şu şekilde devam etmektedir. İkinci bölümde literatürdeki çalışmalar özetlenmiştir. Üçüncü bölümde analizde kullanılan yöntemlerin ekonometrik metodolojisi açıklanmıştır. Dördüncü bölümde veri seti tanımlanmış, ampirik analiz aşamaları açıklanmış ve bulgular yorumlanmıştır. Son olarak beşinci bölümde ampirik bulgulara dayalı çıkarsamalar yapılarak politika önerilerinde bulunulmuştur.

\section{Literatür Taraması}

CDS primleri ve kredi derecelendirme notları ile BIST 100 endeksi arasındaki ilişki literatürde genel olarak incelenmiştir. Tablo 1'de literatürdeki çalışmalara ilişkin özet bilgiler yer almaktadır.

Tablo 1. Literatür Özeti

\begin{tabular}{|c|c|c|c|c|}
\hline Yazar & Örneklem & Değişkenler & Dönem & Sonuç \\
\hline \multicolumn{5}{|c|}{ Panel A: Türkiye'ye ilişkin çalışmalar } \\
\hline $\begin{array}{l}\text { Balive } \\
\text { Y1lmaz } \\
(2012)\end{array}$ & Türkiye & $\begin{array}{l}\text { IMKK } 100 \\
\text { endeksi ile ülke } \\
\text { kredi temerrüt } \\
\text { takası marjları }\end{array}$ & $2002-2012$ & $\begin{array}{l}\text { Pay piyasası (IMKKB } 100 \text { Endeksi) ile CDS marjları arasın- } \\
\text { da ters yönlü bir ilişki mevcuttur. }\end{array}$ \\
\hline $\begin{array}{l}\text { Hanc1 } \\
(2014)\end{array}$ & Türkiye & $\begin{array}{l}\text { CDS dağılımları } \\
\text { ile BIST } 100 \\
\text { getirileri }\end{array}$ & $2008-2012$ & $\begin{array}{l}\text { CDS ile BIST } 100 \text { getirileri arasında ters yönlü bir ilişki } \\
\text { mevcuttur. }\end{array}$ \\
\hline $\begin{array}{l}\text { Kaya } \\
(2015)\end{array}$ & Türkiye & $\begin{array}{l}\text { Derecelendirme } \\
\text { notları ve CDS }\end{array}$ & $\begin{array}{l}01.01 .2007- \\
22.04 .2014\end{array}$ & $\begin{array}{l}\text { Sonuçlar Derecelendirme notları ile CDS primleri arasında } \\
\text { anlamlı bir ilişkinin olduğunu göstermiştir. }\end{array}$ \\
\hline $\begin{array}{l}\text { Değir- } \\
\text { menci ve } \\
\text { Pabucçu } \\
(2016)\end{array}$ & Türkiye & $\begin{array}{l}5 \text { yillık CDS } \\
\text { primleri ile Borsa } \\
\text { İstanbul Hisse } \\
\text { Senedi değerleri }\end{array}$ & $2009-2014$ & $\begin{array}{l}\text { CDS primleri ile hisse senetleri arasında ters yönlü bir ilişki } \\
\text { söz konusudur. }\end{array}$ \\
\hline $\begin{array}{l}\text { Bursa ve } \\
\text { Kadilar } \\
(2016)\end{array}$ & Türkiye & $\begin{array}{l}\text { CDS, BIST 100, } \\
\text { döviz sepeti, ge- } \\
\text { nel bütçe dengesi } \\
\text { ve finansmanı, } \\
\text { ihracatın ithalatı } \\
\text { aylık karşılama } \\
\text { oranı }\end{array}$ & $\begin{array}{l}01.2011- \\
10.2014\end{array}$ & $\begin{array}{l}\text { BIST } 100 \text { endeksinin değerinin bilinmesinin CDS primleri } \\
\text { hakkındaki belirsizliği önemli oranda kaldırdığını göster- } \\
\text { mektedir }\end{array}$ \\
\hline $\begin{array}{l}\text { Çelik } \\
\text { ve Koç } \\
(2016)\end{array}$ & Türkiye & $\begin{array}{l}\text { CDS ve BIST } \\
100\end{array}$ & $\begin{array}{l}08.10 .2008- \\
09.06 .2016\end{array}$ & $\begin{array}{l}\text { Granger Nedensellik Testi sonucunda, CDS ile BIST } 100 \\
\text { arasında çift yönlü nedensel bir ilişki olduğu sonucuna ula- } \\
\text { şılmıştır. }\end{array}$ \\
\hline $\begin{array}{l}\text { Kayhan } \\
\text { Adigüzel } \\
\text { ve Bayat. } \\
(2016)\end{array}$ & Türkiye & $\begin{array}{l}\text { BIST } 100 \text { en- } \\
\text { deksi ve CDS } \\
\text { primleri }\end{array}$ & $2009-2015$ & $\begin{array}{l}\text { Türkiye ekonomisinde CDS primlerindeki göreli değiş- } \\
\text { meler BIST } 100 \text { 'ü etkilemektedir. Prim farkının açılması } \\
\text { durumunda hisse senedi endeksi düşmektedir. }\end{array}$ \\
\hline $\begin{array}{l}\text { Bektur } \\
\text { ve Malc1- } \\
\text { oğlu } \\
(2017)\end{array}$ & Türkiye & $\begin{array}{l}\text { BIST } 100 \text { en- } \\
\text { deksi ve CDS } \\
\text { primleri }\end{array}$ & $\begin{array}{l}12.10 .2000- \\
17.02 .2017\end{array}$ & $\begin{array}{l}\text { CDS'den BIST } 100 \text { 'e tek yönlü nedensellik göstermek- } \\
\text { tedir. BIST } 100 \text { 'deki negatif şokların CDS primine gelen } \\
\text { negatif şokları etkilerken; CDS primine gelen pozitif şoklar } \\
\text { BIST } 100 \text { 'e gelen pozitif şokları etkilemektedir. }\end{array}$ \\
\hline
\end{tabular}




\begin{tabular}{|c|c|c|c|c|}
\hline $\begin{array}{l}\text { Yild1- } \\
\text { rım ve } \\
\text { diğerleri } \\
(2018)\end{array}$ & Türkiye & $\begin{array}{l}\text { Borsa İstanbul } \\
\text { altı endeks verisi } \\
\text { ve derecelendir- } \\
\text { me notları. }\end{array}$ & $2012-2016$ & $\begin{array}{l}\text { Notların endeksleri yüzde yüz etkilemediği vurgulanmak- } \\
\text { tadır. }\end{array}$ \\
\hline $\begin{array}{l}\text { Şahin ve } \\
\text { Özkan } \\
(2018)\end{array}$ & Türkiye & $\begin{array}{l}\text { CDS, döviz kuru } \\
\text { ve BIST } 100\end{array}$ & 2012-2017 & $\begin{array}{l}\text { Yapılan analizler sonucunda BIST } 100 \text { ve CDS arasında } \\
\text { iki yönlü nedensel bir ilişkinin var olduğu, BIST } 100 \text { ile } \\
\text { döviz kurları arasında ise nedensel bir ilişkinin bulunma- } \\
\text { dığı görülmüştür. }\end{array}$ \\
\hline \multicolumn{5}{|c|}{ Panel B: Diğer ülkelere ilişkin çalışmalar } \\
\hline $\begin{array}{l}\text { Fung ve } \\
\text { diğerleri } \\
(2008)\end{array}$ & $\mathrm{ABD}$ & $\begin{array}{l}\text { Hisse senedi ve } \\
\text { kredi temerrüt } \\
\text { takası piyasaları. }\end{array}$ & $2001-2007$ & $\begin{array}{l}\text { Sonuçlar, Hisse senetleri ve CDS'ler arasında bir ilişkinin } \\
\text { var olduğu göstermiştir. Hisse senedi piyasasında fiyatlan- } \\
\text { dırma sürecinde CDS endeksinin, yatırımın derecesini yön- } \\
\text { lendirdiği sonucuna ulaşılmıştır. }\end{array}$ \\
\hline $\begin{array}{l}\text { Chan ve } \\
\text { Zhang } \\
(2009)\end{array}$ & $\begin{array}{l}\text { Çin, Japon- } \\
\text { ya, Güney } \\
\text { Kore, } \\
\text { Endenozya, } \\
\text { Malezya, } \\
\text { Filipinler ve } \\
\text { Tayland }\end{array}$ & $\begin{array}{c}\text { CDS ve hisse } \\
\text { senedi piyasaları. }\end{array}$ & $2001-2007$ & $\begin{array}{l}\text { Sonuçlar, hisse senedi endeksleri ile CDS primleri arasında } \\
\text { güçlü bir negatif korelasyon olduğunu göstermektedir. }\end{array}$ \\
\hline $\begin{array}{l}\text { Norden } \\
\text { ve Weber } \\
(2009)\end{array}$ & $\begin{array}{l}\text { Avrupa, } \\
\text { ABD ve } \\
\text { Asya'dan } \\
90 \text { firma }\end{array}$ & $\begin{array}{l}\text { CDS primleri, } \\
\text { tahvil fiyatları } \\
\text { ve hisse senedi } \\
\text { piyasası. }\end{array}$ & $2000-2002$ & $\begin{array}{l}\text { Sonuçlar doğrultusunda, hisse senedi değişkenin CDS } \\
\text { primleri ve tahvil fiyatlarında değişimlere neden olduğu } \\
\text { sonucuna ulaşılmıştır. }\end{array}$ \\
\hline $\begin{array}{l}\text { Şensoy } \\
\text { Eraslan } \\
\text { ve Erturk } \\
(2016)\end{array}$ & $\begin{array}{l}11 \text { geliş- } \\
\text { mekte olan } \\
\text { ülke }\end{array}$ & $\begin{array}{l}\text { Fitch, Moody's } \\
\text { ve S\&P }\end{array}$ & $2000-2015$ & $\begin{array}{l}\text { Analiz sonuçlarına göre dercelendirme notlarının çoğunun } \\
\text { çift korelasyon üzerinde anlamlı bir etkisi olmadığı sonu- } \\
\text { cuna ulaşılmışıtır. }\end{array}$ \\
\hline
\end{tabular}

Kredi derecelendirme notları, CDS primleri ve pay piyasaları arasındaki ilişki ile ilgili çalışmalar gelişmiş ve gelişmekte olan ülke grupları için literatürde geniş bir şekilde araştırılmıştır. Türkiye için yapılmış çalışmalar da kredi derecelendirme notları, CDS ve BIST 100 arasındaki ilişkide farklı ekonometrik yöntemler kullanılarak değişkenler arasındaki ilişkiye değişik açılardan odaklanıldığı görülmektedir. İncelenen çalışmalar genel olarak ele alındığında ise değişkenler arasındaki nedensellik ilişkisinin araştırıldığı dikkat çekmektedir. Analiz için çalışmada ARDL eşbütünleşme yönteminin seçilmesinin literatüre değişkenler arasındaki ilişkinin farklı bir açıdan değerlendirilmesi yönünden bir katkı sağlayabileceği düşünülmektedir. Çalışmada ilgili üç değişkenin bir arada ele alınması ve çalışma döneminin güncel olması yine literatüre katkı kapsamında düşünülen diğer noktalardır.

CDS primlerinin yükselmesi yatırımcılar tarafından risk olarak alg1lanmaktadır. Bu nedenle genel olarak piyasadan beklenen, pay piyasalarının buna tepkisinin düşüş yönünde olmasıdır. CDS priminin düşmesinin ise yatırımcilar tarafindan olumlu olarak algilanması ve bunun sonucu olarak endeksin yükselmesi yönündedir. Literatürde Türkiye üzerine yapılan çalışmalar incelendiğinde CDS ve BIST 100 arasında genel olarak negatif (ters) yönlü bir ilişki tespit edildiği görülmektedir. Ayrıca nedensellik ilişkisinde de tek yönlü 
ve çift yönlü nedensellik ilişkisi bulunmuştur. (Fung ve diğerleri, 2008; Chan ve Zhang, 2009; Balı ve Y1lmaz, 2012; Hanc1, 2014; Bursa ve Kadılar, 2016; Değirmenci ve Pabucçu, 2016; Kayhan ve diğerleri 2016; Çelik ve Koç, 2016; Bektur ve Malcığlu, 2017; Şahin ve Özkan, 2018).

Derecelendirme notları ile ilgili yapılan çalışmalarda farklı sonuçlar ortaya çıkmaktadır. Kaya ve diğerleri (2015) olayların anlamlı bir etkiye sahip olup olmadığ 1 ve eğer anlamlı bir etkiye sahipse bu etkinin yönünün, CDS primleri ile derecelendirme notları arasında ve hatta üç farklı kuruluşun derecelendirme notları arasında dahi farklılık gösterebildiğini vurgulamaktadır. Tüm olaylar için bir değerlendirme yapıldığında ise, derecelendirme notlarının CDS primlerine nazaran daha fazla olayın etkisini içeriğinde barındırdığı ifade etmektedir. Yıldırım ve diğerleri (2018), açıklanan notların altı endeks üzerinde yarı yarıya etkili olduğu tespit edilmiş olup nihai sonuç olarak notların endeksleri yüzde yüz etkilemediği vurgulanmaktadır. Tutar, Tutar ve Eren (2011), sonuç olarak yatırımcıların yüksek kredi notu verilen ülkelere yatırım yaptığını ifade etmişlerdir. Fakat finansal krizlerden sonra önemli şirketlerin batmasından dolayı bu kuruluşlara karşı güven sorununun ortaya çıktığını vurgulamışlardır. Derecelendirme notları üzerine yapılan çalışmalarda notların önemine vurgu yapılmakta olup yaşanan mali krizlerden dolayı derecelendirme kuruluşlarına karşı yaşanan güven kaybının da vurgulandığı dikkat çekmektedir.

\section{Yöntem}

\subsection{Veri Seti ve Değişkenler}

Analizde 2010:2-2020:2 dönemini kapsayan aylık veriler kullanılmıştır. Değişkenler arasındaki ölçek farklılıklarından doğabilecek etkinin ortadan kaldırılabilmesi için verilerin doğal logaritmaları alınmış ve analizde logaritmik formları kullanılmıştır. Analizler Eviews-10 paket programı aracılığıyla yapılmıştır. Analizde kullanılan verilere ilişkin açıklamalar ve verilerin elde edildiği kaynaklar Tablo 2'de listelenmiştir. 
Tablo 2. Değişkenler ve Tanımlamalar

\begin{tabular}{lll}
\hline Değișken & Tanım & Kaynak \\
\hline BIST 100 & $\begin{array}{l}\text { Borsa İstanbul Kapanış Endekslerini } \\
\text { ifade etmektedir. }\end{array}$ & $\begin{array}{l}\text { https://tr.investing.com/indices/ise-100- } \\
\text { historical-data }\end{array}$ \\
\hline CDS & $\begin{array}{l}\text { Türkiye'ye ilişkin CDS (credit defa- } \\
\text { ult swap) primlerini ifade etmektedir. }\end{array}$ & $\begin{array}{l}\text { https://tr.investing.com/rates-bonds/turkey-cds- } \\
\text { 5-year-usd-historical-data }\end{array}$ \\
\hline SP & $\begin{array}{l}\text { Standart \& Poor Derecelendirme (Ra- } \\
\text { iting) kuruluşunun Türkiye'ye ilişkin } \\
\text { derecelendirmesini ifade etmektedir. }\end{array}$ & \\
\hline FIttps://tradingeconomics.com/turkey/rating \\
& $\begin{array}{l}\text { Fitch Derecelendirme (Raiting) kuru- } \\
\text { luşunun Türkiye'ye ilişkin derecelen- } \\
\text { dirmesini ifade etmektedir. }\end{array}$ & \\
\hline MOODYS & $\begin{array}{l}\text { Moody's Derecelendirme (Raiting) } \\
\text { kuruluşunun Türkiye'ye ilişkin dere- } \\
\text { celendirmesini ifade etmektedir. }\end{array}$ & \\
\hline
\end{tabular}

Derecelendirme notlarının sayısal veriye çevrilmesinde kullanılan yöntem, Ismailescu ve Kazemi (2010) ve Gande ve Parsley (2005) çalışmaları ile S\&P, Fitch ve Moodys derecelendirme tanımlama raporları doğrultusunda oluşturulmuştur. Bu doğrultuda Tablo 3'te S\&P derecelendirme kuruluşunun notlandırma sisteminin sayısal karşılıkları listelenmiştir.

Tablo 3. S\&P Kredi Notlandırma Görünümlerine Sayısal Değerler Atanması

\begin{tabular}{lc}
\hline Kredi Notu & Sayısal Değeri \\
\hline $\mathrm{AAA}^{-}$ & 17 \\
$\mathrm{AA}^{+}$ & 16 \\
$\mathrm{AA}$ & 15 \\
$\mathrm{AA}^{-}$ & 14 \\
$\mathrm{~A}^{+}$ & 13 \\
$\mathrm{~A}$ & 12 \\
$\mathrm{~A}^{-}$ & 11 \\
$\mathrm{BBB}^{+}$ & 10 \\
$\mathrm{BBB}^{-}$ & 9 \\
$\mathrm{BBB}^{-}$ & 8 \\
$\mathrm{BB}^{+}$ & 7 \\
$\mathrm{BB}^{-}$ & 6 \\
$\mathrm{BB}^{-}$ & 5 \\
$\mathrm{~B}^{+}$ & 4 \\
$\mathrm{~B}^{-}$ & 3 \\
$\mathrm{~B}^{-}$ & 2
\end{tabular}




\begin{tabular}{lc}
$\mathrm{CCC}^{+}$ile CCC- notlandırma aralığı için & 1 \\
$\mathrm{CCC}$ - altı notlandırmalar için & 0 \\
$\mathrm{SD}$ (Varsayılan) & -1 \\
\hline & \\
\hline Kredi değişimlerinin notlandırılması & 0.5 \\
\hline Pozitif & 0.25 \\
Pozitif izlenim & 0 \\
Sabit durum & -0.25 \\
Negatif izlenim & -0.5 \\
Negatif & \\
\hline
\end{tabular}

Kaynakça: Ismailescu ve Kazemi, (2010, s. 2872)

Tablo 4'te ise S\&P derecelendirme kuruluşu notlandırma sisteminin Moody's ve Fitch derecelendirme kuruluşlarının kullandığg notlandırma sistemindeki karşı1lkları listelenmiştir.

Tablo 4. S\&P, Moody's ve Fitch Derecelendirme Kuruluşu Not Sitemi

\begin{tabular}{ccc}
\hline $\begin{array}{c}\text { S\&P Derecelendirme } \\
\text { Notları }\end{array}$ & $\begin{array}{c}\text { Moody's Derecelendirme } \\
\text { Norları }\end{array}$ & $\begin{array}{c}\text { Fitch Derecelendirme } \\
\text { Notları }\end{array}$ \\
\hline AAA & Aaa & AAA \\
AA & Aa & AA \\
A & A & A \\
BBB & Baa & BBB \\
BB & $\mathrm{Ba}$ & BB \\
B & $\mathrm{B}$ & B \\
CCC & $\mathrm{Caa}$ & $\mathrm{CCC}$ \\
$\mathrm{CC}$ & $\mathrm{Ca}$ & $\mathrm{CC}$ \\
$\mathrm{R}$ & $\mathrm{C}$ & $\mathrm{C}$ \\
$\mathrm{SD}$ & & $\mathrm{RD}$ \\
\hline
\end{tabular}

Kaynakça: S\&P, Moody's ve Fitch derecelendirme kuruluşları raporları

Analizde ilgili kuruluşların örneklem döneminde Türkiye için verdikleri derecelendirme notları Tablo 3 ve Tablo 4 doğrultusunda sayısallaştırılarak kullanılmıştır. 


\subsection{Model}

CDS primleri ve kredi derecelendirme notları ile BIST 100 endeksi arasındaki ilişki Türkiye özelinde incelendiği temel fonksiyon Eşitlik 1'de gösterildiği gibidir:

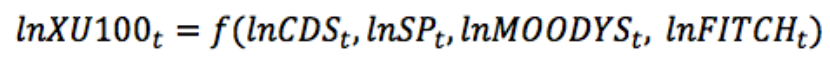

Temel fonksiyonun doğrusal formda gösterimi şu şekildedir:

$$
\operatorname{lnXU100}{ }_{t}=\alpha+b t+\varphi_{1} \operatorname{lnCDS_{t}}+\varphi_{2} \operatorname{lnSP}_{t}+\varphi_{3} \operatorname{lnMOODYS}_{t}+\varphi_{4} \operatorname{lnFITCH}_{t}+\mu_{t}
$$

Burada $\alpha$ sabit terimi, $b t$ trendi ve $\ln$ logaritma işlemini ifade etmektedir.

\subsection{Ekonometrik Methodoloji}

CDS primleri, derecelendirme notları ve BIST arasındaki uzun dönemli ilişki eşbütünleşme yaklaşımı ile incelenecektir. Hangi eşbütünleşme testinin uygulanacağına karar verebilmek için serilerin kaçıncı seviyeden durağan oldukları incelenmesi gerekmektedir. Bu noktada Dickey ve Fuller (DF) (1979), Genişletilmiş Dickey ve Fuller (ADF) (1981), Philips ve Peron (PP) (1989) ve Kwiatkowski, Phillips, Schmidt ve Shin (KPSS) (1992) testlerinden yararlanılmıştır.

\subsection{Dickey ve Fuller (1979) Birim Kök Testi}

DF birim kök testine ilişkin temel model Eşitlik 3’te gösterildiği gibidir.

$$
Y_{t}=\rho Y_{t-1}+\varepsilon_{t}
$$

Burada $Y_{t}$ bağımlı değişkeni, $Y_{t-1}$, bağımlı değişkenin bir dönem önceki gecikmelerini ifade etmektedir. Temel model sabit terim ve trend içerecek şekilde genişletebilmektedir. DF testine ilişkin hipotezler şu şekildedir:

$H_{0}: \rho=1$ (Seri birim kök içermektedir.)

$H_{A}: \rho<1$ (Seri durağandır.)

DF testine ilişkin test istatistiği Eşitlik 4'te gösterildiği gibidir.

$$
\hat{\tau}=\frac{\hat{\rho}-1}{\operatorname{sh}(\widehat{\rho})}
$$

DF testine ilişkin karar süreci şu şekildedir; hesaplanan istatistik değeri kritik değerden büyük ise $H_{0}$ hipotezi reddedilmektedir. Yani bu durumda serinin durağan olduğu (birim kök içermediği) sonucuna ulaşılmaktadır. 


\subsection{Genişletilmiş Dickey ve Fuller (1981) Birim Kök Testi}

ADF birim kök testi DF testinin genişletilmiş versiyonudur. Bu testte serilerde oluşabilecek değişen varyans ve/veya otokorelasyon sorunu, bağımlı değişkenin gecikmelerinin modele bağımsız değişken olarak dahil edilmesiyle giderilebilmektedir. Buna göre ADF testi Eşitlik 5'te gösterildiği gibidir.

$$
\Delta Y_{t}=a_{o}+b t+\alpha Y_{t-1}+\theta_{1} \Delta Y_{t-1}+\theta_{2} \Delta Y_{t-2}+\cdots+\theta_{q} \Delta Y_{t-q}+\varepsilon_{t}
$$

Eşitlik 5'te yer alan denklem daha kapalı formda şu şekilde ifade edilebilmektedir (Dickey ve Fuller, 1981, s. 1065):

$$
\Delta Y_{t}=a_{o}+b t+\alpha Y_{t-1}+\sum_{j=1}^{q} \theta_{j} \Delta Y_{t-j}+\varepsilon_{t}
$$

Burada $\theta$ gecikme katsayısı, $q$ gecikme boyunu gösteren parametre ve $\alpha=1-\rho$ 'dir. ADF testine ilişkin hipotezler şu şekildedir:

$H_{0}: \alpha=0$ (Seri birim kök içermektedir.)

$H_{A}: \alpha<0$ (Seri durağandır.)

ADF testine ilişkin test istatistiği Eşitlik 6'da gösterildiği gibidir.

$$
\hat{\tau}=\frac{\widehat{\alpha}}{\operatorname{sh}(\widehat{Q})}
$$

$\mathrm{ADF}$ testindeki karar verme süreci DF testinde açıklanan süreç ile aynidir.

\subsection{Philips ve Perron (1989) Birim Kök Testi}

PP testi ADF testinden farklı olarak hata terimindeki otokorelasyonu parametrik olmayan yaklaşım kullanarak düzeltmektedir. PP testine ilişkin temel model Eşitlik 7'de gösterildiği gibidir:

$$
\Delta Y_{t}=a_{o}+b t+\alpha Y_{t-1}+\varepsilon_{t}
$$

Denklemde $\alpha_{0}$, sabit terimi, $t$ ise trendi temsil etmektedir. PP testine ilişkin test istatistikleri şu şekildedir:

$$
\begin{aligned}
& Z_{\widehat{\alpha}}=T \hat{\alpha}-\left(\widehat{\omega}^{2}-\hat{\sigma}_{\varepsilon}^{2}\right)\left(2 T^{-2} \sum_{t=1}^{T} \hat{\varepsilon}_{t}^{2}\right)^{-1} \\
& z_{t}=t_{\hat{\alpha}}\left(\frac{\partial_{\tilde{E}}^{2}}{\widehat{\omega}^{2}}\right)^{1 / 2}-\frac{1}{2}\left(\widehat{\omega}^{2}-\hat{\sigma}_{\varepsilon}^{2}\right)\left(\widehat{\omega}^{2} T^{-2} \sum_{t=1}^{T} \hat{\sigma}_{\varepsilon}^{2}\right)^{-1 / 2}
\end{aligned}
$$

Eşitlik 8 ve 9'da yer alan $\hat{\sigma}_{\varepsilon}^{2}$, kalıntıların varyansını, $T$ gözlem sayısını ve $\hat{\omega}^{2}$ tutarlı uzun dönem varyans tahmincisini ifade etmektedir. PP testine ilişkin hipotezler şu şekildedir:

$$
\begin{aligned}
& H_{0}: \alpha=0 \text { (Seri birim kök içermektedir.) } \\
& H_{A}: \alpha<0 \text { (Seri durağandır.) }
\end{aligned}
$$


PP testindeki karar verme süreci DF testinde açıklanan süreç ile aynıdır.

\subsection{Kwiatkowski, Phillips, Schmidt ve Shin (1992) Durağanlık Testi}

KPSS testine ilişkin temel model Eşitlik 10'da gösterildiği gibidir.

$$
Y_{t}=a_{o}+b t+r_{t}+\varepsilon_{t}
$$

Burada $\alpha_{o}$, sabit terimi, $t$, trendi, $r_{t}$, rassal yürüyüş sürecini ve $\varepsilon_{t}$, durağan hataları ifade etmektedir. Eşitlik 10'da yer alan $r_{t}$, terimi Eşitlik 10.1'de gösterildiği gibi tanımlanmaktadır.

$$
r_{t=} r_{t-1}+u_{t}, \quad u_{t} \sim\left(0, \sigma_{u}^{2}\right)
$$

KPSS testinde yokluk hipotezi diğer birim kök testlerinden farklı olarak seri durağandır şeklinde kurulmaktadır. Buna göre KPSS testine ilişkin hipotezler şu şekildedir.

$$
\begin{aligned}
& H_{o}: \sigma_{u}^{2}=0 \text { (Seri durağandır.) } \\
& H_{A}: \sigma_{u}^{2}>0 \text { (Seri birim kök içermektedir.) }
\end{aligned}
$$

KPSS testine ilişkin test istatistiği Eşitlik 11'de gösterildiği gibidir.

$$
K P S S=\frac{1}{T^{2}} \frac{\sum_{t=1}^{T} S_{t}^{2}}{\partial_{\varepsilon}^{2}}
$$

Burada $\hat{S}_{t}=\sum_{j=1}^{t} \tilde{\varepsilon}_{j}$ şeklinde hesaplanmaktadır. $\hat{\sigma}_{\varepsilon}^{2}$ 'nin hesaplanmasında kernel (çekirdek) tahmincilerden yararlanılmaktadır. KPSS testindeki karar verme sürecinde hesaplanan istatistik değeri KPSS (1992) çalışmasında yer alan kritik değerler ile karşılaştırılmaktadır. Test istatistiğinin kritik değerden büyük olması durumunda $H_{o}$ hipotezi kabul edilmekte ve serinin durağan olduğuna karar verilmektedir.

Değişkenler arasındaki ilişkinin EKK yaklaşımı ile incelenmesinde serilerin durağan olduğu varsayılmaktadır. Bu varsayımın ihlal edilmesi yani serilerin durağan olmaması durumunda EKK yaklaşımı ile yapılan tahminler sapmalı ve tutarsız olacaktır. Bu noktada durağan olmayan seriler arasındaki ilişkilerin incelenmesinde eşbütünleşme yaklaşımı yoğun olarak kullanılmaktadır. Literatürdeki eşbütünleşme testleri sahip oldukları varsayımlar doğrultusunda farklılıklar göstermektedir. Bu çalışmada varsayımların incelenmesi sonucunda Peseran, Shin ve Smith (2001) tarafından geliştirilen ARDL eşbütünleşme testinin kullanılmasına karar verilmiştir.

\subsection{Peseran ve diğerleri (2001) ARDL Eşbütünleşme Testi}

ARDL eşbütünleşme testinin kullanılabilmesi için temel varsayım bağımlı değişkenin I(1) bağımsız değişken (ler)in ise I(0) ve/veya I(1) sürece 
sahip olması gerekmektedir. Unutulmaması gereken diğer bir varsayım da hiçbir serinin I(2) veya üstü dereceden durağanlığa sahip olmaması gerekmektedir. Bu noktada çalışmada ilk olarak birim kök testleri yardımıyla serilerin durağanlık seviyeleri analiz edilerek kullanılacak modelin ARDL testine uygunluğu test edilmiştir.

CDS primleri ve kredi derecelendirme notları ile BIST 100 endeksi arasındaki eşbütünleşme ilişkisinin incelendiği ARDL modeli Eşitlik 12'de gösterildiği gibidir.

$\Delta \operatorname{lnXU100} t=a_{0}+\delta_{1} \operatorname{lnCDS} S_{t-1}+\delta_{2} \operatorname{lnSP}_{t-1}+\delta_{3} \operatorname{lnMOODYS}_{t-1}+\delta_{4} \operatorname{lnFITCH}_{t-1}+\sum_{i=1}^{k} \beta_{1 i} \Delta(\operatorname{lnCDS})_{t-i}+$

$\sum_{i=1}^{l} \beta_{2 i} \Delta(\operatorname{lnSP})_{t-i}+\sum_{i=1}^{m} \beta_{3 i} \Delta(\operatorname{lnMOODYS})_{t-i}+\sum_{i=1}^{n} \beta_{4 i} \Delta(\operatorname{lnFITCH})_{t-i}+\emptyset_{i} E C T_{t-1}+\varepsilon_{t}$

Burada $\Delta$, fark operatörüdür. $k, l, m$ ve $n$ gecikme uzunluklarıdır. Kısa dönem ilişkiler farkı alınmış seriler ile modellenmektedir. $\alpha_{0}$ sabit terimi ifade etmektedir. $\delta_{j}$ ve $\beta_{j}$ kısa dönem katsayılardır. $\varnothing$ hata düzeltme katsayısıdır ve kısa dönemdeki dengesizliklerin ne kadar sürede düzeleceğini ifade etmektedir.

Bu noktadan sonra uzun dönemde değişkenler arasında eşbütünleşme ilişkisinin varlığı Pesaran ve diğerleri (2001) tarafından önerilen Sınır (Boounds) testi yaklaşımı ile test edilmektedir. Buna göre eşbütünleşmenin varl1ğını inceleyen hipotezler aşağıda gösterildiği gibidir:

$$
\begin{gathered}
H_{o}: \rho=\delta_{1}=\delta_{2}=\cdots=\delta_{k}=0 \text { (Eşbütünleşme yoktur.) } \\
H_{o}: \rho \neq \delta_{1} \neq \delta_{2} \neq \cdots \neq \delta_{k} \neq 0 \text { (Eşbütünleşme vardır.) }
\end{gathered}
$$

Karar verme aşamasında analiz sonucu elde edilen $\mathrm{F}$ istatistiğinin alt sınır ve üst sınırlar kritik değerlerinin sağına, soluna veya ortasına gelme durumu incelenmektedir. Eşbütünleşme ilişkisinin varlığına Tablo 2'de gösterildiği gibi karar verilmektedir.

Tablo 5. Karar Tablosu

\begin{tabular}{l|l|l}
\hline $\mathbf{I}(\mathbf{0})$ & & $\mathbf{I}(\mathbf{1})$ \\
\hline$H_{o}:$ KABUL & Kararsızlık Bölgesi & $\begin{array}{l}H_{o}: \text { RED } \\
\text { Eşbütünleşme vardır. }\end{array}$ \\
\hline Eşbütünleşme yoktur. & & . \\
\hline
\end{tabular}

Tablo 5'de I(0) alt sınırı, I(1) üst sinırı ifade etmektedir. Buna göre elde edilen istatistik değeri alt sınırın altına gelmesi durumunda $H_{o}$ hipotezi kabul edilir ve eşbütünleşme ilişkisinin olmadığına karar verilir. Üst sınırın üstüne gelmesi durumunda $H_{o}$ hipotezi reddedilerek eşbütünleşme ilişkisinin var olduğuna karar verilir. Alt sınır ile üst sınırın arasına gelmesi durumunda ise eşbütünleşme ilişkisinin varlığına ilişkin bir karara varılamamaktadır. 


\section{Ampirik Analiz}

Analizde kullanılan değişkenler arasındaki eşbütünleşme ilişkisinin varlığının incelenebilmesi için ilk olarak değişkenlere ilişsin birim kök sınamalarının yapılması gerekmektedir. Tablo 6' da birim kök testlerine ait sonuçlar listelenmiştir.

Tablo 6. Birim kök analiz sonuçları

\begin{tabular}{|c|c|c|c|c|c|c|c|c|}
\hline \multirow{4}{*}{ Değişkenler } & \multicolumn{2}{|l|}{ DF } & \multicolumn{2}{|l|}{$\mathrm{ADF}$} & \multicolumn{2}{|l|}{ PP } & \multicolumn{2}{|c|}{ KPSS } \\
\hline & \multicolumn{8}{|c|}{ Seviye } \\
\hline & & lag & İstatistik & $\operatorname{lag}$ & İstatistik & $\begin{array}{l}\text { Band- } \\
\text { width }\end{array}$ & İstatistik & $\begin{array}{l}\text { Band- } \\
\text { width }\end{array}$ \\
\hline & \multicolumn{8}{|c|}{ Sabitli Model } \\
\hline $\ln X U 100$ & -0.645 & 0 & -2.359 & 0 & -2.326 & 11 & $1.161 * * *$ & 9 \\
\hline $\ln C D S$ & $-2.001^{* *}$ & 0 & -2.206 & 0 & -2.152 & 2 & $0.682 * *$ & 9 \\
\hline $\ln S P$ & -0.326 & 0 & -0.649 & 0 & -0.650 & 1 & $0.892 * * *$ & 9 \\
\hline InMOODYS & -0.894 & 0 & -0.715 & 0 & -0.729 & 1 & $0.637 * *$ & 9 \\
\hline \multirow[t]{2}{*}{$\ln F I T C H$} & 0.956 & 0 & 0.690 & 0 & 0.947 & 5 & $0.803^{* * *}$ & 9 \\
\hline & \multicolumn{8}{|c|}{ Sabitli and Trendli Model } \\
\hline $\ln X U 100$ & $-3.020^{*}$ & 0 & -2.975 & 3 & $-3.619 * *$ & 5 & $0.199^{* *}$ & 8 \\
\hline $\ln C D S$ & $-3.122 * *$ & 0 & $-3.229^{*}$ & 0 & $-3.225^{*}$ & 1 & 0.074 & 8 \\
\hline $\ln S P$ & -1.666 & 0 & -1.944 & 0 & -1.944 & 0 & $0.275^{* * *}$ & 9 \\
\hline InMOODYS & -1.222 & 0 & -1.862 & 0 & -1.862 & 0 & $0.311^{* * *}$ & 9 \\
\hline \multirow[t]{4}{*}{$\ln F I T C H$} & -0.692 & 0 & -0.825 & 0 & -0.637 & 5 & $0.317^{* * *}$ & 9 \\
\hline & \multicolumn{8}{|c|}{ Birinci Fark } \\
\hline & İstatistik & lag & İstatistik & $\operatorname{lag}$ & İstatistik & $\begin{array}{l}\text { Band- } \\
\text { width }\end{array}$ & İstatistik & $\begin{array}{l}\text { Band- } \\
\text { width }\end{array}$ \\
\hline & \multicolumn{8}{|c|}{ Sabitli Model } \\
\hline $\ln X U 100$ & -0.604 & 0 & $-10.966 * * *$ & 0 & $-12.469 * * *$ & 19 & 0.186 & 18 \\
\hline $\ln C D S$ & $-9.827 * * *$ & 0 & $-11.722 * * *$ & 0 & $-11.763^{* * *}$ & 6 & 0.057 & 7 \\
\hline $\ln S P$ & $-10.950 * * *$ & 0 & $-10.947 * * *$ & 0 & $-10.948 * * *$ & 2 & 0.129 & 2 \\
\hline InMOODYS & $-10.923 * * *$ & 0 & $-10.893 * * *$ & 0 & $-10.893 * * *$ & 2 & 0.289 & 2 \\
\hline \multirow[t]{2}{*}{ InFITCH } & $-11.016^{* * *}$ & 0 & $-11.084 * * *$ & 0 & $-11.088^{* * *}$ & 3 & $0.483 * *$ & 3 \\
\hline & \multicolumn{8}{|c|}{ Sabitli and Trendli Model } \\
\hline $\ln X U 100$ & -1.854 & 0 & $-10.946 * * *$ & 0 & $-12.464 * * *$ & 19 & 0.076 & 18 \\
\hline $\ln C D S$ & $-10.731 * * *$ & 0 & $-11.686^{* * *}$ & 0 & $-11.726^{* * *}$ & 6 & 0.030 & 7 \\
\hline $\ln S P$ & $-11.049 * * *$ & 0 & $-10.965 * * *$ & 0 & $-10.965^{* * *}$ & 3 & 0.041 & 3 \\
\hline InMOODYS & $-11.108 * * *$ & 0 & $-11.087 * * *$ & 0 & $-11.102 * * *$ & 4 & 0.018 & 4 \\
\hline $\ln F I T C H$ & $-11.420 * * *$ & 0 & $-11.393 * * *$ & 0 & $-11.6368 * * *$ & 7 & 0.069 & 7 \\
\hline
\end{tabular}

***, **, * sirasıyla $\% 1, \% 5, \% 10$ 'daki anlamlılık düzeyini ifade etmektedir. Veri setinin aylık olması nedeniyle maksimum gecikme uzunluğu 12 olarak belirlenmiş ve uygun gecikme sayısı Schwarz bilgi kriterine göre belirlenmiştir. PP ve KPSS Testlerinde Newey West yöntemlerine göre, Bartlett Kernel tahmincisi kullanılmıştır.

Birim kök analizlerine ilişkin sonuçlar incelendiğinde bağımlı değişken

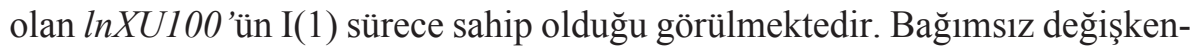


lere ilişkin sonuçlar incelendiğinde $\ln C D S$ değişkeni dışında tüm değişkenlerin I(1) sürece sahip olduğu görülmüştür. $\ln C D S$ değişkeninin ise sabitli ve trendli modelde $\mathrm{I}(0)$ sürece sahip olduğu görülmüştür. Birim kök test sonuçları doğrultusunda bağımlı değişkenin I(1) bağımsız değişken (ler)in ise I(0) ve/veya I(1) sürece sahip olmasına izin veren ARDL eşbütünleşme testinin kullanılmasına karar verilmiştir.

Geleneksel eşbütünleşme testleri değişkenlerin aynı düzeyde durağan olması gerektiği varsayımına sahiptir. Ancak ARDL testi farklı seviyelerde durağan olan (I(0), I(1)) değişkenlere uygulanabilmektedir. Tablo 7'de tüm bağımsız değişkenlerin modelde yer aldığı genel modele ilişkin eşbütünleşme sonuçları listelenmiştir.

Tablo 7. ARDL (4, 1, 0, 0, 1) Tahmin Sonuçları (Model 1)

\begin{tabular}{|c|c|c|c|}
\hline Eşbütünleşme & F-istatistik & Anlamlılık Seviyesi & $\mathbf{I}(\mathbf{0})-\mathbf{I}(\mathbf{1})$ \\
\hline \multirow[t]{3}{*}{$\operatorname{ARDL}(4,1,0,0,1)$} & $7.3579 * * *$ & $\% 10$ & $3.16-4.23$ \\
\hline & & $\% 5$ & $3.67-4.84$ \\
\hline & & $\% 1$ & 4.89-6.16 \\
\hline Uzun dönem katsayılar & Katsayı & \multicolumn{2}{|c|}{ T-istatistik (Prob.) } \\
\hline $\ln C D S$ & -0.3971 & \multicolumn{2}{|c|}{$-10.0809 * * *$} \\
\hline $\operatorname{lnSP}$ & -0.3536 & \multicolumn{2}{|c|}{$-3.0286^{* * *}$} \\
\hline InMOODYS & 0.0129 & \multicolumn{2}{|c|}{0.1534} \\
\hline $\operatorname{lnFITCH}$ & 0.1369 & \multicolumn{2}{|c|}{0.6779} \\
\hline \multicolumn{4}{|l|}{ Hata düzeltme modeli } \\
\hline $\operatorname{ECM}(-1)$ & -0.5037 & \multicolumn{2}{|c|}{$-6.1788^{* * *}$} \\
\hline Tanısal test sonuçları & F-istatistik & \multicolumn{2}{|c|}{ Prob. } \\
\hline Breusch-Godfrey LM Test & 1.241601 & \multicolumn{2}{|c|}{0.2671} \\
\hline Heteroskedasticity Test (White) & 1.5193 & \multicolumn{2}{|c|}{0.1352} \\
\hline $\begin{array}{l}\text { Heteroskedasticity Test (Breusch- } \\
\text { Pagan Godfrey) }\end{array}$ & 1.4044 & \multicolumn{2}{|c|}{0.1815} \\
\hline Ramsey Reset Test & 1.3231 & \multicolumn{2}{|c|}{0.2526} \\
\hline
\end{tabular}

Tablo 7'deki sonuçlar incelendiğinde hesaplanan F-istatistiği (7.357) tüm anlamlılık seviyelerindeki üst sınırlardan büyük olduğu için $H_{o}$ hipotezi reddedilmiştir ve değişkenler arasında eşbütünleşme ilişkisinin var olduğu sonucuna ulaşılmıştır. Yani CDS primleri ve derecelendirme notları ile BIST 100 endeksi uzun dönemde birlikte hareket etmektedir. Eşbütünleşme ilişkisinin tespit edilmesinden sonra değişkenlere ilişkin uzun dönem katsayılar incelenmiştir. CDS primleri ve SP derecelendirme notlarının BIST 100 endeksi üzerine etkisinin negatif ve anlamlı olduğu sonucuna ulaşılmıştır. MOODYS ve FITCH derecelendirme notlarının BIST 100 endeksi üzerindeki etkisi ise anlamsız olduğu görülmüştür. Bu nedenle derecelendirme notlarının ayrı ayrı olarak modele dahil edildiği 3 farklı model tahmini yapılmıştır ve CDS prim- 
leri ve derecelendirme notları ile BIST 100 endeksi arasındaki eşbütünleşme ilişkisi tekrar incelenmiştir. Modellere ilişkin sonuçlar Tablo 8, 9 ve 10'da listelenmiştir.

Tablo 8. ARDL $(4,1,0)$ Tahmin Sonuçları (Model 2)

\begin{tabular}{|c|c|c|c|}
\hline Eşbütünleşme & F-istatistik & $\begin{array}{l}\text { Anlamlılık } \\
\text { Seviyesi }\end{array}$ & $\mathbf{I}(\mathbf{0})-\mathbf{I}(\mathbf{1})$ \\
\hline \multirow[t]{3}{*}{$\operatorname{ARDL}(4,1,0)$} & $13.9113 * * *$ & $\% 10$ & $4.30-5.22$ \\
\hline & & $\% 5$ & $5.06-6.10$ \\
\hline & & $\% 1$ & $6.73-8.05$ \\
\hline Uzun dönem katsayılar & Katsayı & \multicolumn{2}{|c|}{ T-istatistik (Prob.) } \\
\hline $\ln C D S$ & -0.4202 & \multicolumn{2}{|c|}{$-10.9129 * * *$} \\
\hline $\ln S P$ & -0.2532 & \multicolumn{2}{|c|}{$-4.5552 * * *$} \\
\hline \multicolumn{4}{|l|}{ Hata düzeltme modeli } \\
\hline ECM $(-1)$ & -0.5397 & \multicolumn{2}{|c|}{$-6.5191^{* * *}$} \\
\hline Tanısal test sonuçları & F-istatistik & \multicolumn{2}{|c|}{ Prob. } \\
\hline Breusch-Godfrey LM Test & 1.2390 & \multicolumn{2}{|c|}{0.2682} \\
\hline Heteroskedasticity Test (White) & $2.3096^{* *}$ & \multicolumn{2}{|c|}{0.0251} \\
\hline $\begin{array}{l}\text { Heteroskedasticity Test (Breusch-Pa- } \\
\text { gan Godfrey) }\end{array}$ & $2.1572 * *$ & \multicolumn{2}{|c|}{0.0363} \\
\hline Ramsey Reset Test & 1.489 & \multicolumn{2}{|c|}{0.163} \\
\hline
\end{tabular}

Tablo 9. ARDL (4, 1, 0) Tahmin Sonuçları (Model 4)

\begin{tabular}{|c|c|c|c|}
\hline Eşbütünleşme & F-istatistik & $\begin{array}{l}\text { Anlamlılık } \\
\text { Seviyesi }\end{array}$ & $\mathbf{I}(\mathbf{0})-\mathbf{I}(\mathbf{1})$ \\
\hline \multirow[t]{3}{*}{$\operatorname{ARDL}(4,1,0)$} & $8.7301 * * *$ & $\% 10$ & $4.30-5.22$ \\
\hline & & $\% 5$ & $5.06-6.10$ \\
\hline & & $\% 1$ & $6.73-8.05$ \\
\hline Uzun dönem katsayılar & Katsayı & \multicolumn{2}{|c|}{ T-istatistik (Prob.) } \\
\hline $\ln C D S$ & -0.4154 & \multicolumn{2}{|c|}{$-8.0247 * * *$} \\
\hline $\ln M O O D Y S$ & -0.0947 & \multicolumn{2}{|c|}{$-1.9524^{*}$} \\
\hline \multicolumn{4}{|l|}{ Hata düzeltme modeli } \\
\hline $\operatorname{ECM}(-1)$ & -0.4150 & \multicolumn{2}{|c|}{$-5.1643^{* * *}$} \\
\hline Tanısal test sonuçları & F-istatistik & \multicolumn{2}{|c|}{ Prob. } \\
\hline Breusch-Godfrey LM Test & 0.7444 & \multicolumn{2}{|c|}{0.7048} \\
\hline Heteroskedasticity Test (White) & $2.8723 * *$ & \multicolumn{2}{|c|}{0.0061} \\
\hline $\begin{array}{l}\text { Heteroskedasticity Test (Breusch-Pa- } \\
\text { gan Godfrey) }\end{array}$ & $2.6561 * *$ & \multicolumn{2}{|c|}{0.0106} \\
\hline Ramsey Reset Test & 1.5121 & \multicolumn{2}{|c|}{0.3526} \\
\hline
\end{tabular}

$*, * *$ ve $* * *$ sirasıyla $\% 1, \% 5$ ve $\% 10$ ve anlamlılık düzeylerini ifade etmektedir. 
Tablo 10. ARDL $(4,1,0)$ Tahmin Sonuçları (Model 3)

\begin{tabular}{lccc} 
Eşbütünleşme & F-istatistik & $\begin{array}{c}\text { Anlamlılık } \\
\text { Seviyesi }\end{array}$ & I(0) - I(1) \\
ARDL $(4,1,0)$ & $8.2144 * * *$ & $\% 10$ & $4.30-5.22$ \\
& & $\% 5$ & $5.06-6.10$ \\
& & $\% 1$ & $6.73-8.05$ \\
Uzun dönem katsayılar & Katsayı & T-istatistik (Prob.) \\
lnCDS & -0.4048 & $-8.0914 * * *$ \\
lnFITCH & -0.1709 & $-2.1259^{* *}$ \\
Hata düzeltme modeli & & \\
ECM (-1) & -0.4305 & $-5.0099^{* * *}$ \\
Tanısal test sonuçları & F-istatistik & Prob. \\
Breusch-Godfrey LM Test & 0.9115 & 0.5386 \\
Heteroskedasticity Test (White) & 2.6008 & 0.0093 \\
Heteroskedasticity Test $\quad$ (Breusch-Pa- & 2.3982 & 0.4401 \\
gan Godfrey) & 1.1238 & \multicolumn{2}{c}{0.4236} \\
Ramsey Reset Test & &
\end{tabular}

Tablo 8, 9 ve 10 'daki sonuçlar genel olarak incelendiğinde modellere ilişkin F-istatistiklerinin tüm anlamlılık seviyelerinde hesaplanan üst sınırlardan büyük olması nedeniyle eşbütünleşme ilişkisinin var olduğu sonucuna ulaşılmıştır. Derecelendirme notlarının ayrı ayrı dahil edilmesiyle tahmin edilen yeni modellerde derecelendirme notları olan SP, MOODYS ve FITCH değişkenlerine ilişkin uzun dönem katsayılar anlamlı çıkmıştır. CDS primlerindeki \%1'lik artış BIST 100 endeksini ortalama olarak \%0.40 azaltmaktadır. SP firmasının açıkladığı derecelendirme notundaki \%1'lik artış BIST 100 endeksini \%0.25 azaltmaktadır. MOODYS firmasının açıkladığı derecelendirme notundaki \%1'lik artış BIST 100 endeksini \%0.09 azaltmaktadır. Son olarak, FITCH firmasının açıkladığı derecelendirme notundaki \%1'lik artış BIST 100 endeksini \%0.17 azaltmaktadır. Modellere ilişkin kısa dönem hata düzeltme katsayıları (ECM(-1)) incelendiğinde tüm modellerde anlamlı, negatif ve birden küçük olduğu görülmüştür. Bu kısa dönem hata düzeltme mekanizmas1nın çalıştığını göstermektedir. ECM katsayısı uzun dönemde meydana gelen sapmaların bir dönem sonra ne kadarının düzeleceğini göstermektedir. Tablo 7, 8 ve 9'daki kısa dönem hata düzeltme katsayısına ilişkin sonuçlar incelendiğinde uzun dönem sapmaların sırasıla $\% 53, \% 43$ ve $\% 41$ 'inin bir sonraki dönemde düzeltildiği sonucuna ulaşılmıştır.

\section{Sonuç}

CDS primleri, derecelendirme notu ve BIST 100 arasındaki ilişkinin araştırıldığı bu çalışmada değişkenler arasındaki ilişki ARDL eşbütünleşme 
yaklaşımı ile incelenmiştir. Analiz sonuçları doğrultusunda CDS'ler ve Derecelendirme Notu ile BIST 100 değişkenlerinin eşbütünleşik olduğu görülmüştür. Bu ilişki değişkenlerin uzun dönemde birlikte hareket ettiğini göstermekte olup yatırımcı açısından dikkate alınabilecek bir bilgi sunmaktadır.

Uzun dönem katsayılar incelendiğinde tüm modellerde CDS primleri ve derecelendirme notu ile BIST 100 arasında negatif yönde istatiksel olarak anlamlı bir ilişkinin var olduğu göstermiştir. Çalışmanın sonuçları kullanılan yöntemler farklılık gösterse de analiz sonuçları yönünden Balı ve Yılmaz (2012), Hanc1 (2014), Değirmenci ve Pabucçu (2016) ve Kayhan ve diğerleri (2016) çalışmaları ile bulguları açısından paralellik göstermektedir. Derecelendirme kuruluşlarının vermiş olduğu notlar artarken piyasaların bu durumu olumlu olarak algılaması beklenmektedir. Oysa bulgularımız katsayıların negatif olduğu yani kredi derecelendirme notları artarken BIST 100'ün tepkisinin olumsuz olduğunu göstermektedir. Pay piyasaları krizler, afetler gibi olaylara hızlı tepki veren ekonomik yapılardır. Kredi derecelendirme notlarındaki olumlu gelişmeye BIST 100'ün olumsuz tepkisi derecelendirme kuruluşlarının güvenilirliğinin özellikle 2008 Küresel Ekonomik Krizi ve 2010 Avrupa Borç Krizinden sonra tartışılmaya başlamasıyla ilişkili olabileceği varsayılmaktadır.

Derecelendirme kuruluşlarının vermiş olduğu notlar yatırımcılar aç1sından dikkate alınmaktadır. Bundan dolayı kuruluşlara ait uzun dönem katsayılardaki yüzdeler açısından SP'nin notundaki \%1'lik artış BIST 100'ü \%0.25 azaltmakta, MOODYS'in notundaki \%1'lik artış BIST 100'ü \%0.09 azaltmakta ve FITCH'in notundaki \%1'lik artış BIST 100'ü \%0.17 azaltmaktadır. $\mathrm{Bu}$ bulgu politika yapıcılara ve yatırımcılara kuruluşların açıkladığı derecelendirme notlarını takip ederken; borç alanlar açısından, göreli risklerini ayırt etmesi konusunda, borç verenler açısından ise kredi verme kararı, fiyatlandırma, izleme ve karşılık ayırma gibi konularda istatistiksel bilgi sağlayarak yardımcı bir bilgi sunabilecektir.

Türkiye gibi ekonomisi kırılgan özelliğe sahip olan ülkelerin derecelendirme notlarının ve CDS primlerinin ülke risklerini yansıtmasından dolayı uluslararası yatırımcıların portföylerine ilgili ülkelerin pay piyasalarındaki hisse senetlerini dahil etmeleri açısından çalışmamızın bulguları kayda değer bir bilgi sunmaktadır. Son olarak çalışmanın bulgularına bakarak ilerde gelişmiş veya gelişmekte olan ülke pay piyasaları bu doğrultuda incelenerek literatüre katk1 sağlanabileceği düşünülmektedir. Değişkenlerin seviyelerinde birim kök içermesi veya durağan olmasından dolayı farklı ekonometrik yöntemler kullanılarak çalışmalar yapılarak literatüre katkı sağlanabilir. 


\section{Kaynakça}

Balı, S., Yılmaz, Z. (2012). Kredi Temerrüt Takası Marjları ile İMKB 100 Endeksi Arasındaki İlişki. 16. Finans Sempozyumu Bildiriler Kitabı, 83-104.

Bektur, Ç., Malcıŏlu, G. (2017). Kredi Temerrüt Takasları ile BIST 100 Endeksi Arasındaki İlişki: Asimetrik Nedensellik Analizi. Bolu Abant İzzet Baysal Üniversitesi Sosyal Bilimler Enstitüsü Dergisi, 17(3), 73-83.

Bursa, N., Kadılar, G. Ö. (2016). Investigation of Turkey Credit Default Swaps with Entropy Concept. Eurasian Eononometrics. Statistics and Emprical Economics Journal, 3(3), 23-32.

Chan, K. C, Fung, H., Zhang, G. (2009). On the Relationship Between Asian Sovereign Credit Default Swap Markets and Equity Markets. Journal of Asia Business Studies, 4(1), 3-12.

Çelik, S., Koç, D. (2016). Relationship Between Sovereign Credit Default Swap And Stock Markets: The Case Of Turkey. The Macrotheme Review, 5(4), 36-40.

Dickey, D. A., Fuller, W. A. (1979). Distribution Of The Estimators For Autoregressive Time Series With A Unit Root. Journal Of The American Statistical Association, 74(366a), 427 431.

Dickey, D.A., Fuller, W.A. (1981). Likelihood Ratio Statistics For Autoregressive Time Series With A Unit Root. Econometrica, 49(4), 1057-1072.

Değirmenci, N., Pabucçu, H. (2016). Risk Primi ile BİST-100 Etkileşiminin İncelenmesi. 17.Uluslararası Ekonometri, Yöneylem Araştırması ve İstatistik Sempozyumu Bildiriler Kitab1, 101-102.

Fung, H., Sierra, G. E., Yau, J. G. (2008). Are The U.S. Stock Market and Credit Default Swap Market Related? Evidence From The CDX Indices. Journal of Alternative Investments, 11(1), 43-61.

Gande, A., D.C. Parsley (2005). News Spillovers in The Sovereign Debt Market. Journal Of Financial Economics, 75, 691-734.

Hancı, G. (2014). Kredi Temerrüt Takasları Ve BİST-100 Arasındaki İlişkinin İncelenmesi. Maliye Finans Yazıları, 28(102), 9-22.

Ismailescu, I., H. Kazemi (2010). The Reaction Of Market Credit Default Swap Spreads To Sovereign Credit Ratings Changes. Journal Of Banking And Finance, 34, 2861-2873.

Kwiatkowski, D., Phillips, P. C., Schmidt, P., Shin, Y. (1992). Testing The Null Hypothesis Of Stationarity Against The Alternative Of A Unit Root. Journal Of Econometrics, 54(1-3), 159-178.

Kaya, B., Kaya, E. Ö., Yalçıner, K. (2015). Türkiye'nin Derecelendirme Notları Ve Kredi Temerrüt Swap Primlerinin Ekonomik Ve Sosyal Olaylara Tepkisinin Analizi. Maliye Ve Finans Yazıları, 1(103), 85-111.

Kayhan, S., Adıgüzel, U., Bayat, T. (2016). CDS Primlerinin Borsa Endeksleri Üzerindeki Etkisi: BİST-100 Örneği. 17.Uluslararası Ekonometri, Yöneylem Araştırması ve İstatistik Sempozyumu Bildiriler Kitabı, 2-4 Haziran, Sivas, 290-293.

Norden, L., Weber, M. (2009). The Co-movement of CreditDefault Swap, Bond and Stock Markets: An Empirical Analysis. European Financial Management, 15(3), 529-562. 
Paseran, M. H., Shin, Y., Smith, R. J. (2001). Bounds Testing Approaches to the Analysis of Level Relationships. Journal of Applied Econometrics, 16, 289-326.

Perron, P. (1989). The Great Crash, The Oil Price Shock, and The Unit Root Hypothesis. Econometrica, 57(6), 1361-1401.

Şensoy, A., Eraslan, V., Erturk, M. (2016). Do Sovereign Rating Announcements Have An Impact On Regional Stock Market Co-Movements? The case of Central and Eastern Europe. Economic Systems, 40(4), 552-567.

Şahin, E. E., Özkan, O. (2018). Kredi Temerrüt Takası, Döviz Kuru ve BİST100 Endeksi İlişkisi. Hitit Üniversitesi Sosyal Bilimler Enstitüsü Dergisi, 11(3), 1939-1945.

Tutar, E., Tutar, F., Eren, M. V. (2011). Uluslararası Kredi Derecelendirme Kuruluşlarının Rolü, Güvenirlilik Açısından Sorgulanması ve Türkiye. Akademik Bakış Dergisi, 25, Kırgizistan.

Yıldırım, H., Yıldız, C., Aydemir, Ö. (2018). Kredi Derecelendirme Kuruluşlarından S\&P, Moody's ve Fitch'in Türkiye için Yapmış Oldukları Not Açıklamalarının Hisse Senedi Endeksleri Üzerine Etkisi: Borsa İstanbul Örneği 2012-2016. Maliye ve Finans Yazıları, 1(109), 9-30. 
